\title{
Blended Learning for Emirati Women
}

\section{William Radecki}

Hewlett-Packard, USA

\begin{abstract}
This paper describes a blended learning course for Emirati women combining face-to-face instruction with heavy use of distance learning technologies such as videoconferencing, email and a "virtual classroom". Instructors conducted action research in order to 1) improve course design and teaching methods, 2) share distance teaching insights with colleagues, and 3) advise institutional authorities on IT resource management. Results of the study are presented, and conclusions about the suitability and efficacy of distance learning for Emirati women are offered.
\end{abstract}

\section{Background}

From 1999-2003, I taught English as a Second Language at Zayed University - a women's university with campuses in Dubai and Abu Dhabi, United Arab Emirates (http://www.zu.ac.ae). All students at the University are local Muslim women, while faculty and staff come from all over the globe. Over the last three decades the UAE has grown from a small collection of fishing villages to a modern center of oil production, trade and tourism; and Zayed University is one of a number of tertiary institutions that have been established during this period, guided by Sheikh Zayed bin Sultan al Nahayan, first president of the UAE.

Perhaps the most unique aspect of Zayed University is its impressive information technology infrastructure. All

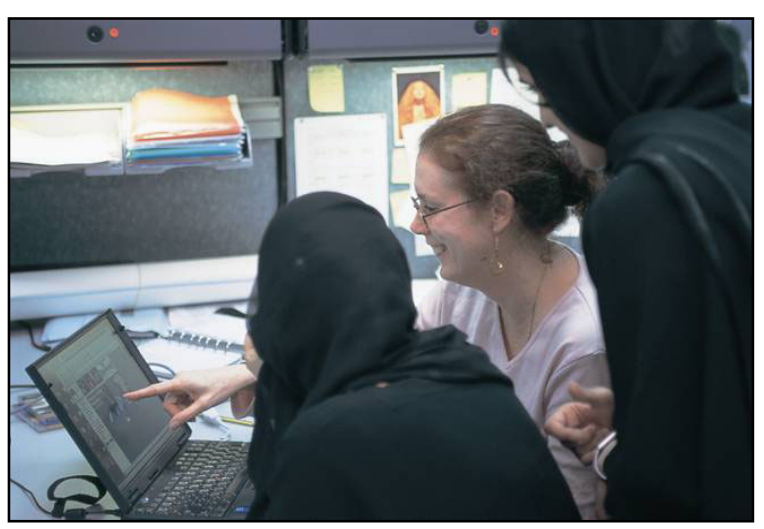
students and teachers have laptops, all classrooms are connected to the Internet, the library subscribes to 20 online databases, and the Blackboard course management system facilitates online course delivery and program administration.

In 2001, the University's IT Department created an "electronic classroom" on each of the two campuses. The rooms were equipped with PictureTel videoconferencing equipment and SMARTBoard interactive whiteboards. Though some teachers had previously tried email exchanges 
with students overseas, the "electronic classroom" presented the first real opportunity to offer distance courses at Zayed University, and possibly the first true distance learning experience for Emirati women.

The United States Distance Learning Association (2004) defines distance learning as "the acquisition of knowledge and skills through mediated information and instruction, encompassing all technologies and other forms of learning at a distance." During the 1990's distance learning advanced well beyond standard correspondence courses, as high-bandwidth Internet technology became more common in homes and schools.

The explosive growth of distance education worldwide makes it difficult to offer definitive statistics on institutional course offering or enrollment, but in 2002 in the US alone an estimated $81 \%$ of the nation's 5000 colleges and universities offered at least one online course (Allen \& Seaman, 2003). According to enrollment statistics from "cyber institutions" like Open University and Phoenix University, demand from the Middle East has kept pace with other regions of the world, and many suggest that distance education is an ideal alternative for those who cannot study overseas for cultural or financial reasons.

\section{Course Objectives}

I was identified, along with a colleague at the other campus, as a candidate for piloting the new electronic classroom. My colleague and I were both "early adopters" of new technologies, and had frequently drawn on the standard laptop and Internet technologies in our English language courses.

Our brief was to initiate a course involving collaboration through distance learning technologies between participants on the two campuses. Our e-classroom pilot course had to fit within the parameters of the English Language Center (ELC) program and the University calendar. That is, it would be a 10-week English language course for pre-baccalaureate students. Classes could meet for up to five hours per week, and the course would be outside the required curriculum (i.e., students would enroll in the course as an elective, or due to minimum hourly requirements for fulltime students).

After much discussion and planning, we proposed a team-taught course for upper level students in the ELC. (The proposal was accepted and we eventually taught five iterations of the course.) We agreed on three key course objectives: 
1.) A focus on developing writing skills. This was the greatest weakness for students in the ELC, and the most common obstacle to satisfying the program's exit requirements and advancing to the baccalaureate level.

2.) Interactive and communicative activities. Distance technologies would not be used simply to distribute or broadcast information to students. Rather, students would use distance technologies to communicate and interact with instructors and with each other.

3.) Collaborative tasks with a public, finished product. The course was not required and letter grades were not awarded, so a collaboratively produced, publicly displayed project was intended to increase motivation and engagement in the course.

While this paper does not focus on language proficiency, it is worth noting that these objectives were based more on research in second language acquisition than on distance learning studies. Specifically, we considered evidence that a task-based, communicative approach is effective with advanced ESL learners (Nunan, 1989; Brown, 1994).

Prior to teaching the course, the readily available distance learning literature was scant and somewhat dated (Moore \& Thompson, 1990; Verduin \& Clark, 1991; Wilkes \& Burnham, 1991), but several themes were consistently emphasized:

- Technological tools should be appropriately applied to learning tasks and teaching methods.

- Teacher feedback must be timely and coherent.

- Interaction between learners should be rich and meaningful.

As Wilkes and Burnham (1991) summarized, many of the pedagogical rules of good face-to-face teaching apply to distance education, though the "toolbox" involved contains unfamiliar tools.

\section{Course Design}

Our course was a 10-week writing course, with all the standard elements of a high-level ESL writing class: defining a topic, gathering information, writing a draft, submitting for peer and teacher review, revising, re-submitting for teacher review, revising and publishing. The challenge was that students would rely on distance technology to complete each of these tasks, collaboratively across the two campuses, in English. The final project was a publicly accessible website, written and 
designed by the class.

There were around 10 students and one teacher at each campus (enrollment varied slightly during the five terms the course was offered). The class met three hours weekly in the "electronic classroom" and two hours a week asynchronously. The first two weeks were spent introducing new communications technologies and negotiating article topics and writing teams. Typically, classes chose to create a website that would serve the university community (e.g., a description of student clubs, or a review of student services, pictured at right).

Between weeks two and seven, students gathered information, outlined, drafted and revised articles,

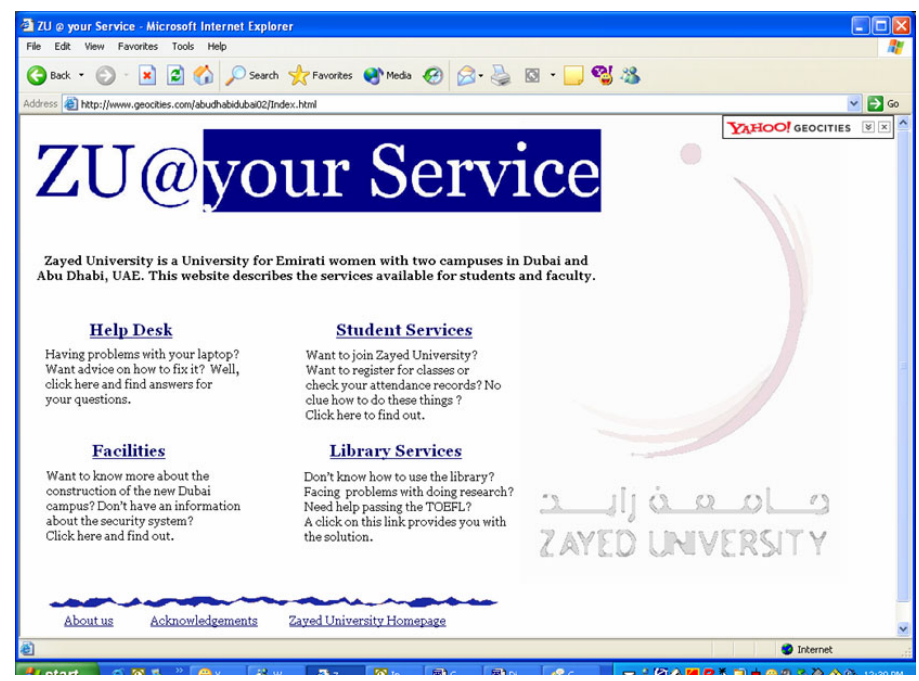
and collected photos and graphics. Within an online course management system (Blackboard), a small group was created for each writing team; teams included 2-4 members, including students from both campuses. Writing teams used the small-group feature of Blackboard to chat, send email and exchange files. Typically, class sessions began by establishing a videoconference connection, and then getting into small-group chat rooms to discuss recent activities, clarify instructions, and plan future efforts. A field trip was also organized for students to visit their counterparts on the other campus.

The last two weeks of the course were spent uploading pictures and articles, and designing web pages. We chose to publish the website on Geocities for the sake of expediency and public access (http://www.geocities.com/crosscampushome/).

\section{Action Research}

Since the course was intended to pilot the University's e-classroom, and we could find no research on the appropriacy or effectiveness of distance learning for Emirati women, my colleague and I recognized the importance of recording student (and teacher) perceptions and behaviors. Our study could be characterized as "action research," defined by Allwright and Bailey (1991) as "a participatory, self-reflective and collaborative approach to [qualitative] research" that involves teachers "taking an action and systematically observing what follows" with the intent of improving educational processes for students, teachers and institutions. Action research is a practical and 
user-friendly way for teachers to understand and improve their own teaching while incrementally adding to the body of research in their field.

There were three primary objectives for our research:

1.) Improve the course design and teaching methods;

2.) Share the advantages and disadvantages of distance teaching with colleagues; and

3.) Advise administrators on e-classroom management and distance program development.

Our aim was not to measure the improvement of writing skills or general English language proficiency, as the sample size, limited written production and numerous external factors (i.e., the students were enrolled in four other intensive ESL classes) would not allow us to state definitively that technology affected performance positively or negatively. However, we did hope to offer some initial insights on the suitability and efficacy of distance learning for Emirati women from a pedagogical and cultural perspective.

We employed four methods of data collection: student course evaluations, personal observations, teaching logs, and Blackboard course site statistics. These methods, and course adjustments made as a result, are described below.

\section{Student Course Evaluations}

Students completed an anonymous course evaluation during week six (see Appendix A). The evaluation sought student opinions and preferences for three key elements of the course: use of Blackboard, videoconferencing, and general course structure. Students in all five iterations of the course consistently rated most elements very highly (8+ on a 10-point scale). They were particularly enthusiastic about communication via videoconference and Blackboard's chat feature. Students also felt their English and IT skills were improving, and they enjoyed meeting students from the other campus.

Two aspects of the course drew comparatively negative responses, however. First, students reacted unfavorably to the suggestion that the course should be taught separately on the two campuses. This result was satisfying, for it showed that the students were discriminating in their answers, rather than simply ticking high values for all questions.

Students also indicated that they disliked seeing themselves on the local videoconference screen. 
Comments offered on the questionnaire suggested that students felt appearing on video was not proper for Muslim women. Although this is common knowledge for teachers in the Middle East, a paraphrase of one student's explanation of this issue may benefit readers who are not from the region: In Islam, a woman's modesty is her most important virtue, and acts such as posing for a photo, uncovering her hair, or shaking hands with a man can bring great shame on her and her family. Emirati women are very protective of their public image, and Zayed University students are especially wary of digital images due to their ease of transmission, public posting and manipulation.

In response to this concern, my colleague and I re-emphasized our explanation that videoconferences were not recorded or broadcast, and compared videoconferencing to other technologies, such as mobile phones and instant messaging, that are used by many students without compromising privacy.

\section{Personal observations}

Another possible explanation for the students' on-camera reticence was suggested by personal observations. In all five iterations of the course, students were noticeably nervous and conscious of their appearance during field trips to the sister campus. One student, who normally did not cover her face, wore a veil for the duration of the trip. An Arab colleague suggested later that, in a nation where marriages are sometimes arranged by word of mouth, appearances in such situations could increase the prospects of a successful match. My colleague and I began to refer to this as the "aesthetic objection" to videoconferencing, and we suspect it rivals or even surpasses other objections to appearing on camera.

To answer this "aesthetic objection," we made two adjustments to the course. First, we eased students into videoconferencing by practicing with the local camera several times before connecting with partners at the other campus. My class staged a "fashion show" (in my absence, to reduce the inhibitions induced by the presence of a male teacher), taking turns posing for the camera and manipulating the zoom and pan features. Students were then much less inhibited during the first "live" videoconference.

Another adjustment was to move the field trip from the seventh to the second week of the term. If students had already met face-to-face, they were more comfortable with close-ups during videoconferences. Another unanticipated result of this adjustment was that friendships formed during the earlier face-to-face meeting served to soften disagreements that, during the first course, 
were aggravated by distance and unfamiliarity.

\section{Teaching logs}

I recorded a weekly teaching log as part of a broader study being conducted by my colleague. These logs were completed only during the fourth of five terms the course was offered, but they pointed to several key refinements of certain materials and activities.

For example, in the Week $5 \log$ (see Appendix B), I describe an attempt to clarify the roles and responsibilities of a group of students I was supervising. There were four students - two on my local campus, and two on the sister campus. I negotiated via "email, chat, and videoconference", but "in some cases, [my colleague] had to 'intervene' and explain things in person" to a student she normally wouldn't supervise. I concluded that "this phase of the course was much more clearly defined than past terms, and I think it was an improvement."

In subsequent iterations of the course, we built face-to-face communication with the on-site instructor into this phase of the course rather than adhering strictly to supervisory group assignments. We realized that this was a compromise, born of expediency, and a luxury that distance teachers without a counterpart on the remote site do not have, but clear understanding of roles and responsibilities was central to a group's success, and certain students responded better to discussing them in person.

\section{Blackboard course statistics}

Blackboard is a proprietary institutional portal that links teachers and learners in an online environment. It was crucial to the management of our distance course, and also provided valuable information for our research. Blackboard served as a common launching pad for each day's lesson and facilitated the distribution of course materials. More importantly, its communication features (i.e., email, chat, and discussion board) made cross-campus collaboration easy, fast and reliable. Creating small groups for each writing team enabled students to share common files and communicate in a space restricted to group members and instructors. Online chat sessions were automatically archived, so my colleague and I could read and comment on student progress after class sessions ended. We also used the "Virtual Classroom" feature to debate and vote on key issues concerning the class.

Another very useful feature of Blackboard was the ability to generate course statistics (see Appendix $\mathrm{C}$ for a partial record from one iteration of the course). Instructors can select different 
"areas" (content, communication, group pages, etc.), and various measures (e.g., total number of hits, hours or days of use, etc.) and generate usage statistics for specific users.

The availability of usage statistics for the course site yielded a dramatic example of action research in the true sense of "taking an action and systematically observing what follows." During the first iteration of the course, the course site received only 5000 hits from students, mostly in the area of content. Students explained that they were retrieving digital handouts from the content area, but conducting most of their communications via GroupWise e-mail, Instant Messenger, or even mobile phone (i.e., technologies that were not archived, and were commonly used in Arabic). At the beginning of the second course offering, we announced that students were required to use Blackboard for all communication, including e-mail and chat. The result was that the total number of hits for all students jumped to around 15,000 during subsequent course offerings, with the majority of hits in the communication and group areas. We felt that, in a task-based course, with all Blackboard communication archived and in English, this was a positive development.

Course statistics also helped us to determine whether individual students were actively engaged in the course. In one case, we found evidence of a particularly quiet student exploring the most remote parts of the course site. She was engaged, but in a way we would not have noticed without Blackboard's archived course statistics.

\section{Conclusions}

This study had three stated objectives:

1.) Improve the course design and teaching methods;

2.) Share the advantages and disadvantages of distance teaching with colleagues; and

3.) Advise administrators on e-classroom management and distance program development.

The most significant alterations to course design and teaching methods resulted from course evaluations, teaching logs and observations, and Blackboard statistics; these are presented above.

My colleague and I perceived several advantages and disadvantages of distance teaching. Among the advantages were the novelty and enlivening challenge of using a new technology, the ability to follow and comment on archived communication between members of student groups, the access to records of course site activity by each member of the class, and the exposure to students and 
the academic atmosphere at the sister campus.

There were, of course, disadvantages. Students reported some frustration with the slow pace of online collaboration and the miscommunication that sometimes resulted from imprecise agreements with their partners at the other campus. Group work can be challenging in any context, but with the added distance between group members, it was especially easy for inactive members to miss deadlines, and disagreements were more difficult to resolve, even with teacher intervention. Also, some students never overcame their on-camera discomfort.

There were challenges for the teachers, as well. The sheer volume of communication between students was impossible to review thoroughly, and many opportunities to offer specific feedback (e.g., on grammar or vocabulary) were missed in order to provide general guidance on group progress. Planning and materials development also required an inordinate amount of time, even after several iterations of the course. However, the additional time and energy applied to this course may not be entirely attributed to the fact that it was taught with distance technologies. It was, after all, a new course, with no textbook, and other teachers did not contribute materials as they would for many required courses. Team-teaching also necessitated close integration and regular communication.

The experience of piloting the e-classroom yielded useful insights on resource management and distance program development. Scheduling and room configuration were problematic, at first. The videoconferencing equipment was frequently used for meetings by cross-campus administrative committees. These meetings sometimes ran into class time, or changes were made to room or equipment configuration that required valuable class time to correct. With a combination of signage, training on proper equipment use, and the cooperation of scheduling staff, most problems were resolved.

Instructors who teach distance courses frequently encounter institutional or procedural issues that negatively affect the quality of the learning experience. In some cases, problems arise simply because distance learning is a novelty, and procedures have not been developed to do it effectively. As pioneers of the technology, early adopters have an excellent opportunity to help develop these procedures and provide feedback and training to others.

Our course suggested that a robust distance education program for Emirati women is feasible, though it may differ slightly from programs in other regions, partly due to cultural considerations. (Note that the range of cultural norms throughout the Arab world makes it difficult to apply these conclusions to other Arab countries). In the present Emirati context, enrollment should be tightly 
controlled, and participants should not include men without the clear consent of students and their families. Photographic images should not be recorded, broadcast or posted to a shared or online resource - a growing concern as broadband Internet connections and webcam technology become standard features of "electronic classrooms." Instructors should receive training on cultural issues of privacy and modesty, and adjustments to teaching practices - such as confidence-building sessions with videoconference equipment - may be required.

While cultural issues may be distinct for female Emirati students in a distance learning context, pedagogical issues are similar to those encountered by distance educators everywhere. That is, the technology must be applied appropriately to the task, positive interaction and relationship building between students and teachers are essential, and feedback must be timely, clear and meaningful. These considerations, highlighted in the somewhat dated resources reviewed prior to developing the course, have been echoed in more current research on distance education (e.g. Sherry, 2000) and extended to include more recent technological innovations such as instant messaging, threaded discussion lists and "virtual classrooms" (Staley \& MacKenzie, 2001).

To the credit of Zayed University's administration, these and other technologies have been made available to Emirati women in the "electronic classroom." This initial investment, followed by systematic piloting and program development, are the first steps toward a robust distance education program. Many higher education institutions throughout the world are discovering that a well-resourced and managed distance program has a dual benefit: the institution can fill underenrolled courses, while remote students can obtain a high-quality education (Berg, 2002). This study suggests that Emirati women respond well to the distance learning environment, as long as cultural considerations are built into the program, and instructors are familiar with the broader issues of effective distance teaching.

\section{Discussion/Reflection Questions}

\section{Discuss}

this paper

1. What distance technologies are available in your context, or are likely to be available in the near future? What possibilities exist for blending distance and face-to-face interaction?

2. How are distance courses likely to change as technological innovations are introduced and become more common in classrooms worldwide? How will these innovations challenge students/institutions where privacy issues are particularly important?

3. What are the ethical implications of course management systems that allow instructors to 
read transcripts of online student interactions and track the days/hours students access the course site?

\section{About the Author}

Will Radecki has 15 years of teaching experience in Africa, Europe and the Middle East. While at Zayed University (1999-2003), he focused on integrating information technology and teaching/learning. He is currently working as a writer for the Emerging Market Solutions group at Hewlett Packard in California, USA.

\section{References}

Allen, I. E., \& Seaman, J. (2003). Sizing the Opportunity: The quality and extent of online education in the United States, 2002, 2003. Needham, MA: SCOLE. Retrieved November 1, 2004 from http://www.sloan-c.org/resources/survey.asp

Allwright, R.L. \& Bailey, K.M. (1991). Focus on the Language Classroom: an introduction to classroom research for language teachers. Cambridge: Cambridge University Press.

Berg, G.A. (2002). Why Distance Learning? Higher Education Administrative Practices. New York: Praeger Publishers.

Brown, H.D. (1994). Teaching by Principles: An Interactive Approach to Language Pedagogy. New Jersey: Prentice Hall Regents.

Moore, M.G. \& Thompson, M.M., with Quigley, A.B., Clark, G.C., \& Goff, G.G. (1990). The Effects of Distance Learning: A summary of the literature. Research Monograph No. 2. University Park, PA: The Pennsylvania State University, American Center for the Study of Distance Education.

Nunan, D. (1989). Designing Tasks for the Communicative Classroom. New York: Cambridge University Press.

Sherry, L. (2000). The Nature and Purpose of Online Conversations: A brief synthesis of current research. International Journal of Educational Telecommunications, 6 (1), 19-52.

Staley, A. \& MacKenzie, N., eds. (2001). Computer Supported Experiential Learning. Birmingham: UCE. 
United States Distance Learning Association. (2004). http://www.usdla.org/.

Verduin, J.R. \& Clark, T.A. (1991). Distance Education: The foundations of effective practice. San Francisco, CA: Jossey-Bass Publishers.

Wilkes, C.W., \& Burnham, B.R. (1991). Adult Learner Motivations and Electronics Distance Education. The American Journal of Distance Education, 5(1), 43-50. 


\section{Appendix A}

\section{Questionnaire for the students of the Distance Web Project course}

\section{Spring B, 2002}

Please answer the following questions carefully and honestly. DO NOT write your name on this questionnaire. Your teachers will use your answers to improve the course.

1.) How do you like using Blackboard to get Course Information (e.g. Course Plan, Weekly Schedules, etc.)?

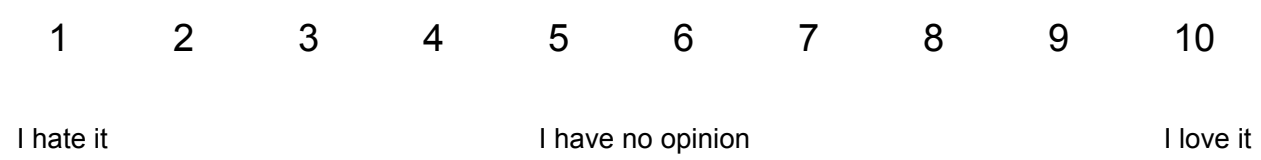

2.) How do you like using Blackboard to get Assignments (e.g., worksheets)?

$\begin{array}{llllllllll}1 & 2 & 3 & 4 & 5 & 6 & 7 & 8 & 9 & 10\end{array}$

3.) How do you like using Blackboard's Discussion Board (where you give your opinion on specific topics over a period of time)?

$\begin{array}{llllllllll}1 & 2 & 3 & 4 & 5 & 6 & 7 & 8 & 9 & 10\end{array}$

I hate it I have no opinion I love it

4.) How do you like using Blackboard's Virtual Classroom (where you chat with classmates)?

$\begin{array}{llllllllll}1 & 2 & 3 & 4 & 5 & 6 & 7 & 8 & 9 & 10\end{array}$

I hate it I have no opinion I love it

5.) How do you like using Blackboard's E-mail system (i.e., selecting students from the course to send email)?

$\begin{array}{llllllllll}1 & 2 & 3 & 4 & 5 & 6 & 7 & 8 & 9 & 10\end{array}$


Learning and Teaching in Higher Education: Gulf Perspectives

I hate it

I have no opinion

I love it

6.) Overall, how do you like using Blackboard?

$\begin{array}{llllllllll}1 & 2 & 3 & 4 & 5 & 6 & 7 & 8 & 9 & 10\end{array}$

I hate it

I have no opinion

I love it

Additional comments about using Blackboard (continue on back if necessary):

[space deleted]

7.) How do you like seeing and hearing your classmates on the videoconference?

$\begin{array}{llllllllll}1 & 2 & 3 & 4 & 5 & 6 & 7 & 8 & 9 & 10\end{array}$

I hate it I have no opinion l love it

8.) How do you like seeing and hearing yourself on the videoconference?

$\begin{array}{llllllllll}1 & 2 & 3 & 4 & 5 & 6 & 7 & 8 & 9 & 10\end{array}$

I hate it I have no opinion I love it

9.) Overall, how do you like using the videoconference room?

$\begin{array}{llllllllll}1 & 2 & 3 & 4 & 5 & 6 & 7 & 8 & 9 & 10 \\ \text { I hate it } & & & \text { I have no opinion } & \end{array}$

Additional comments about using the videoconference room (continue on back if necessary):

[space deleted]

10.) Do you think the Distance Web Project course would be better if students at the two campuses did not work together (i.e., should students at each campus work independently on two different websites, with no communication or cooperation by Blackboard or videoconference)?

$\begin{array}{llllllllll}1 & 2 & 3 & 4 & 5 & 6 & 7 & 8 & 9 & 10\end{array}$

Definitely not

I'm not sure

Definitely, yes

11.) Do you feel you are becoming friends with students at the other campus?

$\begin{array}{llllllllll}1 & 2 & 3 & 4 & 5 & 6 & 7 & 8 & 9 & 10\end{array}$


Learning and Teaching in Higher Education: Gulf Perspectives

Volume 2

Definitely not

I'm not sure

Definitely, yes

12.) Do you think the Distance Web Project (DWP) course is helping you learn English?

$\begin{array}{cccccccccc}1 & 2 & 3 & 4 & 5 & 6 & 7 & 8 & 9 & 10 \\ \text { Definitely not } & & & & & & & & & \end{array}$

13.) Do you think you are learning more Information Technology (IT) in the DWP course?

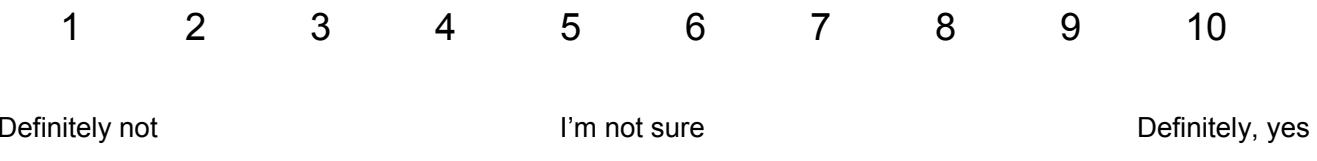

14.) Would you take another distance course if you could?

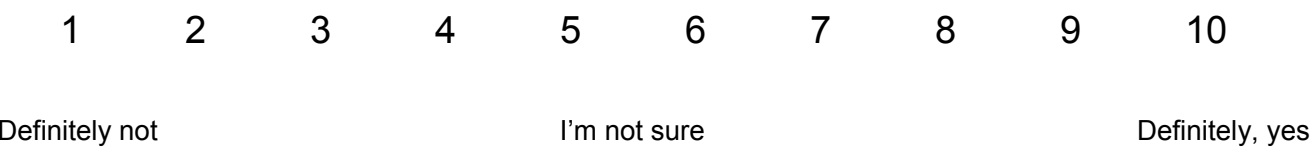

15.) Would you recommend other Readiness students take the Distance Web Project course?

$\begin{array}{rrrrrrrrrr}1 & 2 & 3 & 4 & 5 & 6 & 7 & 8 & 9 & 10 \\ \text { Definitely not } & & & & & & & & & \end{array}$

Additional comments about the Distance Web Project course (What's good? What's bad? How can it be improved?):

[space deleted] 


\section{Appendix B}

\section{Weekly Teacher Log: Week 5}

Description of classroom activities and materials used: Our primary goal this week was to give students time and opportunities to work on their two worksheets - "Organizing our work" and "Assigning responsibilities." The aim, at least for the first two days of the week, was for students to complete these two assignments as a group so that everyone had an accurate picture of how each section of the website would be organized and what each member of the group would do to complete her section. During the second half of the week, we provided feedback on these worksheets and allowed students to begin collecting additional information about their topics. I also used the Tuesday session to teach students how to use digital cameras.

Positive aspects of the course experienced this week: For the most part, students had a fair understanding of what their articles should explain, and how they would gather the information. There were a few cases where students were confused about their part, mainly because the service they were supposed to describe wasn't quite clear to them. We tried a few different ways to give feedback - email, chat, and videoconference. In some cases, the on-site teacher had to "intervene" and explain things in person. This was okay, though, because students hadn't yet expended a lot of energy on gathering information or writing. In fact, this phase of the course was much more clearly defined than past terms, and I think it was an improvement.

As usual, the photography lesson was great. Students love learning this new technology, and it only gets better when we take the photos and alter them with a graphics program the next week.

Negative aspects of the course experienced this week: This was the first big test of the small groups' ability to work together at a distance with only moderate supervision. In some cases, everything went fine, but there were a few cases where students seem to have rubbed each other the wrong way, or there was anxiety because a group member was absent or unresponsive.

Other comments: I'm wondering if we could do something more than the "line up in order blind and mute" exercise to help students anticipate the challenges of working with a partner from a distance. Certainly one of the problems is that some of the students are simply unreliable or unresponsive. For the competent and efficient ones, this is the first time they have had to rely on 
anyone else to complete a task. Another issue is discourse patterns. On several occasions, l've seen students write things (in the chat or in emails) that are, by my standards and norms, startlingly rude. I'm hesitant to address the issue, however, because I'm aware that politeness conventions are culturally bound, and maybe the comments are appropriate between Emirati peers. 


\section{Appendix C}

Sample from the Blackboard course statistics record, Spring 2002 Distance Web Project

Total Accesses Per Area

\begin{tabular}{lrr} 
Area Name & Hits & \multicolumn{2}{c}{ Percent } \\
Communication Areas & 5335 & 36.73 \\
Main Content Areas & 3541 & 24.38 \\
Group Areas & 7525 & 51.82 \\
Student Areas & 301 & 2.072 \\
Total & 16702 & 100
\end{tabular}

Details

COMMUNICATION CONTENT GROUPS STUDENTS Total

\begin{tabular}{|c|c|c|c|c|}
\hline Student 1 & 88 & 120 & 147 & 7 \\
\hline Student 2 & 9 & 112 & 231 & 1 \\
\hline Student 3 & 25 & 26 & 0 & 1 \\
\hline Student 4 & 0 & 0 & 0 & 0 \\
\hline Student 5 & 461 & 224 & 535 & 4 \\
\hline Student 6 & 300 & 322 & 750 & 78 \\
\hline Student 7 & 0 & 0 & 0 & 0 \\
\hline
\end{tabular}




\begin{tabular}{|c|c|c|c|c|c|}
\hline Student 8 & 37 & 32 & 3 & 0 & 72 \\
\hline Student 9 & 308 & 256 & 677 & 20 & 1261 \\
\hline Student 10 & 86 & 28 & 1 & 0 & 115 \\
\hline Student 11 & 164 & 236 & 375 & 4 & 779 \\
\hline Student 12 & 248 & 56 & 288 & 11 & 603 \\
\hline Student 13 & 17 & 36 & 83 & 0 & 136 \\
\hline Student 14 & 211 & 138 & 324 & 6 & 679 \\
\hline Student 15 & 145 & 50 & 214 & 3 & 412 \\
\hline Student 16 & 278 & 274 & 573 & 20 & 1145 \\
\hline Student 17 & 873 & 394 & 485 & 14 & 1766 \\
\hline Student 18 & 358 & 164 & 850 & 15 & 1387 \\
\hline Student 19 & 492 & 246 & 369 & 26 & 1133 \\
\hline Student 20 & 209 & 240 & 409 & 4 & 862 \\
\hline Student 21 & 184 & 114 & 223 & 23 & 544 \\
\hline Student 22 & 54 & 8 & 0 & 0 & 62 \\
\hline Student 23 & 181 & 202 & 122 & 12 & 517 \\
\hline Student 24 & 65 & 107 & 315 & 17 & 504 \\
\hline Student 25 & 57 & 104 & 188 & 29 & 378 \\
\hline Student 26 & 485 & 52 & 363 & 6 & 906 \\
\hline TOTAL & 5335 & 3541 & 7525 & 301 & 16702 \\
\hline
\end{tabular}

